\title{
The international epidemiology of child sexual abuse: A continuation of Finkelhor (1994)
}

\author{
Noemí Pereda $^{\mathrm{a}, *}$, Georgina Guilera $^{\mathrm{b}}$, Maria Forns $^{\mathrm{a}}$, Juana Gómez-Benito ${ }^{\mathrm{b}}$ \\ a Departament de Personalitat, Avaluació i Tractament Psicològics, Facultat de Psicologia, Universitat de Barcelona, Barcelona, Spain \\ b Departament de Metodologia de les Ciències del Comportament, Facultat de Psicologia, Universitat de Barcelona, Barcelona, Spain
}

\section{A R T I C L E I N F O}

\section{Article history:}

Received 15 June 2007

Received in revised form 10 July 2008

Accepted 17 July 2008

Available online 23 May 2009

\section{Keywords:}

Child sexual abuse

Prevalence

Epidemiology

\begin{abstract}
A B S T R A C T
Objective: The purpose of this paper was to compare the prevalence rates of child sexual abuse reported by [Finkelhor, D. (1994). The international epidemiology of child sexual abuse. Child Abuse \& Neglect, 18 (5), 409-417] with those found in recent publications in order to confirm the widespread prevalence of child sexual abuse.

Methods: Relevant articles about prevalence of child sexual abuse were identified through searches of computerized databases and a handsearch of Child Abuse \& Neglect and the Journal of Child Sexual Abuse.

Results: Thirty-eight independent articles were identified, corresponding to 39 prevalence studies; these articles report the prevalence of childhood sexual abuse in 21 different countries, ranging from 0 to $53 \%$ for women and 0 to $60 \%$ for men.

Conclusions: Comparison of the present study with that of [Finkelhor, D. (1994). The international epidemiology of child sexual abuse. Child Abuse $\mathcal{E}$ Neglect, 18 (5), 409-417] shows a similarity between prevalence distributions; there appears to be a general pattern that remains more or less constant over the years, especially in women.

Practice implications: Twelve years after the first revision study about the international prevalence of child sexual abuse, there is still a need for new data about this topic. The present study shows child sexual abuse is still a widespread problem in the society. In this research, carried out on 38 independent studies, there is new data for 21 countries over the world, being especially relevant the results obtained from other countries different from those pertaining to North America or Europe. It is important to point out the high prevalence found in most of the countries, so this information could be a new warning to make society and governments aware of this problem and undertake actions to prevent sexual abuse in childhood.
\end{abstract}

(c) 2009 Elsevier Ltd. All rights reserved.

\section{Introduction}

The widespread prevalence of child sexual abuse has been reported in several countries, thus highlighting the social importance of understanding the nature and scope of this problem. In this regard, epidemiological studies conducted over the last two decades have made important contributions to understanding this problem (Leventhal, 1998). The prevalence of child sexual abuse has been defined as the proportion of a population who have suffered sexual abuse during childhood

\footnotetext{
is This study was supported in part by grants SEJ 2005-09144-C02-01-01 and SEJ 2005-09144-C02-01-02 from the Spanish "Ministerio de Educación y Ciencia" under European Regional Development Fund (ERDF), and 2007FIC00736 and 2005SGR00365 from the "Departament d'Universitats, Recerca i Societat de la Informació de la Generalitat de Catalunya".

* Corresponding author address: Departament de Personalitat, Avaluació i Tractament Psicològics, Facultat de Psicologia, Universitat de Barcelona, Passeig Vall d'Hebron, 171, 08035 Barcelona, Spain.
} 
(generally before the age of 18) and it is based on retrospective accounts. In contrast, incidence studies estimate the number of new child sexual abuse cases occurring during a specified period of time, typically a year (Runyan, 1998). Although results vary considerably, and cannot be compared directly due to substantive methodological differences, they all suggest that child sexual abuse is clearly an international problem. Finkelhor (1994) reviewed the prevalence studies on child sexual abuse from the 1970s to the 1990s. Although the literature included in his review is extremely variable in its scope and quality, he concluded that sexual abuse was reported in all of the studies; specifically, he confirmed a history of sexual abuse in at least $7 \%$ of females and at least 3\% of males, with a range of up to 36\% of women in Austria and 29\% of men in South Africa. As stated by Finkelhor (1994) and by Wynkoop, Capps, and Priest (1995) differences in research methodology (e.g., child abuse definitions, data gathering techniques, populations sampled, the use of broad or more behaviorally specific questions) are thought to account for most of the variance in prevalence rates between studies.

\section{Definition of abuse}

Sexual abuse researchers have used different definitions of what constitutes childhood sexual abuse (e.g., the age difference between the perpetrator and the victim, the age used to define childhood or the type of sexual abuse). Whereas some researchers have set the age of the victim at 18 (e.g., Bendixen, Muus, \& Schei, 1994; Briere \& Elliott, 2003; Collings, 1997), others have used a cut-off both below and above this age (Arreola, Neilands, Pollack, Paul, \& Catania, 2005; Chen, Dunne, \& Han, 2004; Jumaian, 2001). Obviously, such variability influences the estimates of child sexual abuse prevalence in any given sample (Wynkoop et al., 1995).

\section{Measurement issues}

Much of the variability in child sexual abuse prevalence is presumed to be due to methodological differences between studies, especially as regards the methods of data collection (Leventhal, 1998; Wyatt \& Peters, 1986). Peters, Wyatt, and Finkelhor (1986) concluded that face-to-face interviews result in higher reporting rates for prevalence. Other authors, however, have established that self-administered questionnaires probably cause less embarrassment among respondents and produce better response rates than do face-to-face interviews in some societies (Tang, 2002). However, the use of selfadministered questionnaires to identify personal experiences such as sexual abuse increases the risk of false negatives and affects the estimation of prevalence (Berliner \& Conte, 1995; Oates et al., 2000; Wolfe \& Birt, 1997). The number of false negatives is always higher than the number of victims who report false allegations of sexual abuse (Brown, Frederico, Hewitt, \& Sheehan, 2001; Fergusson, Horwood, \& Woodward, 2000).

Reviews have also found that the use of broad questions is associated with lower prevalence rates of sexual abuse than are more behaviorally specific questions (Fricker, Smith, Davis, \& Hanson, 2003). Furthermore, both the context in which sexual victimization questions are asked (Koss, 1993) and the number of questions asked (Finkelhor, 1979) affect endorsement rates.

\section{Sample characteristics}

The gender of participants also seems to affect prevalence rates. Some authors have argued that the study of male sexual victimization was relatively neglected until fairly recently (Dhaliwal, Gauzas, Antonowicz, \& Ross, 1996; Holmes \& Slap, 1998; Romano \& De Luca, 2001), although there are important publications that do address this potential bias (Finkelhor, Hotaling, Lewis, \& Smith, 1990). Several problems have been considered when examining the rates of sexual abuse of males (Violato \& Genuis, 1993), for example, substantially varying prevalence rates (Dhaliwal et al., 1996), the small numbers of sexually abused males who seek professional help for abuse-related difficulties (Holmes, Offen, \& Waller, 1997), and lower rates than those obtained among female victims (e.g., Bouvier et al., 1999; Briere \& Elliott, 2003; Robin, Chester, Rasmussen, Jaranson, \& Goldman, 1997). These confounding variables have resulted in insufficient reporting, recognition and treatment of these samples (for a review of the absence of males in maltreatment research, see Haskett, Marziano, \& Dover, 1996).

Many studies on the prevalence of sexual abuse of minors have been published since 1994, with the strong North American and European contribution being complemented by reports from many other countries (e.g., China, Malaysia, Israel, Palestine, Turkey, and El Salvador). Nevertheless, the situation in most non-English speaking countries remains relatively unexplored (Tang, 2002). The present paper includes studies published subsequent to Finkelhor's review (1994), the aim being to compare his prevalence rates of child sexual abuse with those found in recent publications. We sought to test the hypothesis, as stated by Finkelhor (1994), that child sexual abuse continues to be one of the most important public health problems in all societies in which it has been measured (MacMillan, 1998). In this regard, it was hypothesized that the rates found would be very similar to those obtained over a decade ago and would confirm the widespread prevalence of child sexual abuse.

\section{Methods}

\section{Selection of studies}

Relevant articles about prevalence of child sexual abuse were identified through searches of computerized databases including Medline, Psycinfo, and Science Citation Index and Social Sciences Citation Index of the Web of Science. These databases 


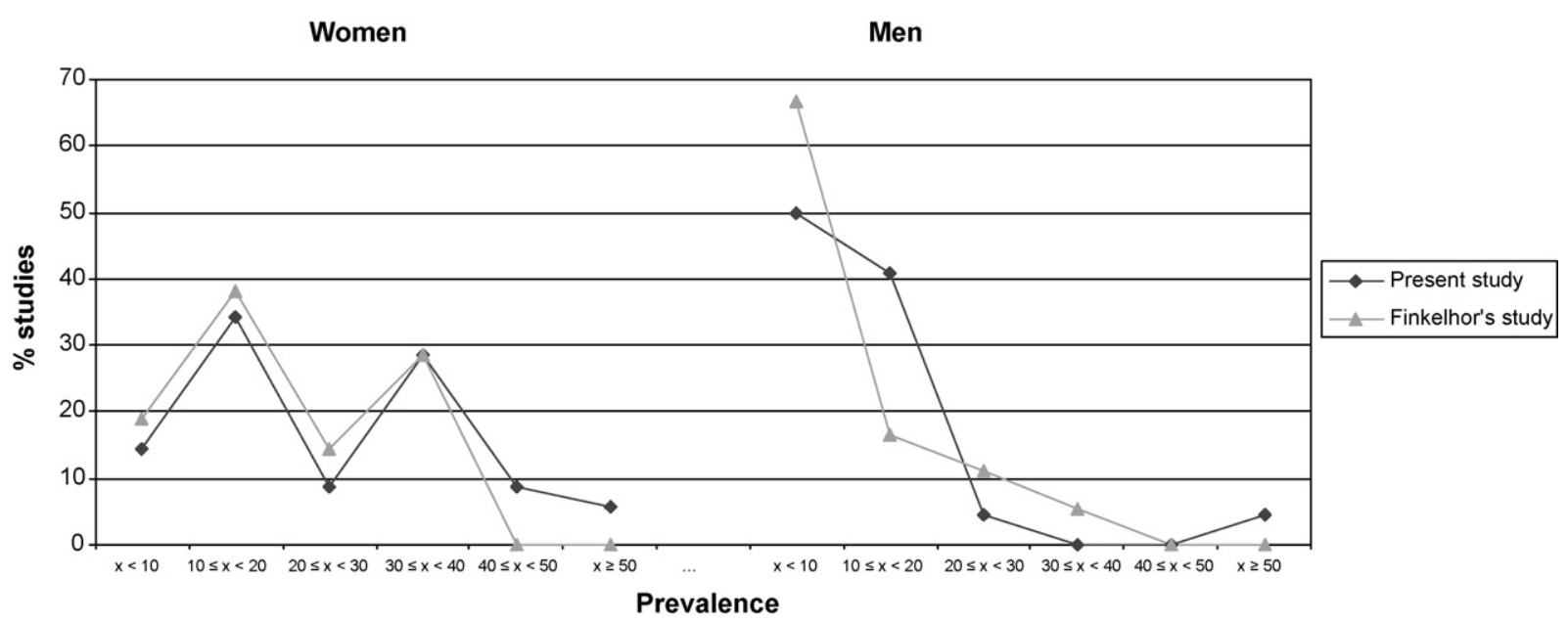

Fig. 1. Percentage of studies according to prevalence rates and gender.

were searched using the key words prevalence, child sexual abuse, and childhood sexual abuse. In order to cover all the available citations, two more strategies were adopted: a reference list review and handsearch in the two journals most relevant to the topic of study, namely Child Abuse $\mathcal{E}$ Neglect and the Journal of Child Sexual Abuse. Studies were included if they met the following criteria: (a) measured prevalence of child sexual abuse; (b) used a non-clinical sample; (c) were written in English; and (d) presented enough information to identify sample size and prevalence. Studies were excluded if they were referred to in Finkelhor's review and if they reported findings from exactly the same sample as another already published study.

\section{Data codification}

Given that the main objective of the present study was to compare Finkelhor's (1994) results with our data, the coded variables, when reported, were as follows: country, number of subjects, subject gender, type of population (general or students), sample area (local or national), type of sampling (probabilistic or non-probabilistic), mode of administration (questionnaire or interview), definition of sexual abuse (broad-includes non-contact sexual abuse, such as exhibitionism and sexual propositions-or narrow-including contact sexual abuse only), response rate, and prevalence for each gender.

After application of the above mentioned search strategies the remaining papers were coded by two psychologists; consensus was always reached in the few cases where disagreement was encountered (kappa $=0.97$ ).

\section{Results}

The present research found a high variability between studies. Thirty-eight independent articles (see * at reference list) were included, corresponding to a total of 39 prevalence studies, the main characteristics of which are shown in Table 1.

These articles present the prevalence of childhood sexual abuse in 21 different countries. The response rates per study range from 65 to $100 \%$ with a mean of $83 \%$, and the number of participants from 65 to 9,953 with a mean of 1646.97 per study. Table 2 illustrates the following aspects of the studies reviewed: most of the studies explore childhood sexual abuse in females, in student populations, and in local areas; with respect to the type of sampling, the majority of studies use a probabilistic design; regarding the mode of administration, this is mostly based on questionnaires; and finally, most of the studies consider a broad definition of child sexual abuse.

In general, the studies confirm a higher prevalence of childhood sexual abuse among women than in men, the two exceptions being the South African study by Madu and Peltzer (2001), where the ratio between females and males was .89, and the study by Figueiredo et al. (2004), where the prevalence for both genders was almost the same (2.7\% in women versus 2.6\% in men). The other articles report female abuse to be between 1.5 (De Paúl, Milner, \& Múgica, 1995 ) and 5.5 (Bendixen et al., 1994) times higher than the rate for males.

The main difference between Finkelhor's (1994) and the present review is that child sexual abuse was not reported by all the studies sampled. One of the studies conducted in China (Ross et al., 2005) surprisingly found no sexual abuse in either women or men. Also noteworthy is the unexpectedly low prevalence of child sexual abuse found in the study from Portugal.

The inclusion of two studies that use different sexual abuse definitions may explain the low prevalence rates encountered (less than 1\%): the study in Finland (Sariola \& Uutela, 1996) only takes into account the incest type of sexual abuse, while the study in France (Choquet, Darves-Bornoz, Ledoux, Manfredi, \& Hassler, 1997) only considers rape.

If we exclude these incest and rape studies, as they refer to a very specific type of sexual abuse, the distribution of prevalence rates from Finkelhor's (1994) and the present review with respect to sample gender is as shown in Fig. 1. In both reviews the majority of studies (66.67 and $50.00 \%$, respectively) report prevalence rates for sexual abuse of male children of 
Table 1

Prevalence rates of child sexual abuse subsequent to $\mathrm{w}$.

\begin{tabular}{|c|c|c|c|c|c|c|c|c|c|c|}
\hline \multirow[t]{2}{*}{ Country } & \multirow[t]{2}{*}{ Author (year) } & \multicolumn{3}{|c|}{ Sample characteristics } & \multirow[t]{2}{*}{ Sampling } & \multirow{2}{*}{$\begin{array}{c}\text { Mode of } \\
\text { administration }\end{array}$} & \multirow[t]{2}{*}{ Response rate } & \multirow[t]{2}{*}{ Definition } & \multicolumn{2}{|c|}{ Prevalence per 100} \\
\hline & & $N$ & Population & Area & & & & & Men & Women \\
\hline \multirow[t]{3}{*}{ Australia } & Mazza et al. (1996) & 2117 & G & $\mathrm{L}$ & $P$ & Q & $72 \%$ & B & - & 39 \\
\hline & Fleming (1997) & 710 & G & $\mathrm{N}$ & $\mathrm{P}$ & $\mathrm{Q}$ & $65 \%$ & $\mathrm{~N}$ & - & 41 \\
\hline & Goldman and Padayachi (1997) & 427 & $\mathrm{~S}$ & $\mathrm{~L}$ & NP & $\mathrm{Q}$ & a & B & 18.60 & 44.60 \\
\hline Canada & MacMillan et al. (1997) & 9953 & G & $\mathrm{N}$ & $P$ & Q & $67 \%$ & B & 4.30 & 12.8 \\
\hline \multirow[t]{3}{*}{ China } & Chen et al. (2004) & 2300 & S & $\mathrm{L}$ & NP & Q & $70 \%$ & B & 10.5 & 16.7 \\
\hline & Ross et al. (2005) & 614 & G & $\mathrm{L}$ & NP & I & $99 \%$ & B & 0 & 0 \\
\hline & Tang (2002) & 2147 & $\mathrm{~S}$ & $\mathrm{~L}$ & NP & Q & $67 \%$ & B & 4.30 & 7.40 \\
\hline El Salvador & Barthauer and Leventhal (1999) & 83 & G & $\mathrm{L}$ & NP & I & $91 \%$ & B & - & 17 \\
\hline Finland & Sariola and Uutela (1996) & 3769 & S & $\mathrm{N}$ & $P$ & Q & $89 \%$ & $\mathrm{~N}^{\mathrm{b}}$ & - & .50 \\
\hline France & Choquet et al. (1997) & 8140 & S & $\mathrm{N}$ & $\mathrm{P}$ & Q & $87 \%$ & $\mathrm{~N}^{c}$ & .60 & .91 \\
\hline \multirow[t]{2}{*}{ Great Britain } & Oaksford and Frude (2001) & 213 & S & $\mathrm{L}$ & NP & Q & $72 \%$ & B & - & 13.14 \\
\hline & May-Chahal and Cawson (2005) & 2869 & G & $\mathrm{N}$ & $\mathrm{P}$ & I & $69 \%$ & B & 11 & 21 \\
\hline Israel & Schein et al. (2000) & 1005 & G & $\mathrm{N}$ & $P$ & Q & $81 \%$ & B & 16 & 31 \\
\hline Jordan & Jumaian (2001) & 100 & S & $\mathrm{L}$ & NP & Q & $100 \%$ & $\mathrm{~N}$ & 27 & - \\
\hline Malaysia & Singh et al. (1996) & 616 & S & $\mathrm{L}$ & NP & Q & $100 \%$ & B & 2.10 & 8.30 \\
\hline Morocco & Alami and Kadri (2004) & 728 & G & $\mathrm{L}$ & $P$ & Q & $67 \%$ & B & - & 9.20 \\
\hline New Zealand & Fergusson, Lynskey, and Horwood (1996) & 1019 & G & $\mathrm{L}$ & NP & I & $81 \%$ & B & 3.40 & 17.30 \\
\hline Norway & Bendixen et al. (1994) & 996 & S & $\mathrm{L}$ & $P$ & Q & $72 \%$ men, $79 \%$ women & B & 3.50 & 19.40 \\
\hline Portugal & Figueiredo et al. (2004) & 835 & $P$ & $\mathrm{~L}$ & $P$ & Q & $69 \%$ & B & 2.60 & 2.70 \\
\hline Singapore & Back et al. (2003) & 88 & S & $\mathrm{L}$ & NP & $\mathrm{Q}$ & a & $\mathrm{N}$ & - & 15.9 \\
\hline \multirow[t]{2}{*}{ South Africa } & Collings (1997) & 640 & S & $\mathrm{L}$ & NP & Q & $100 \%$ & $\mathrm{~N}$ & - & 34.80 \\
\hline & Madu and Peltzer (2001) & 414 & $\mathrm{~S}$ & $\mathrm{~L}$ & $\mathrm{P}$ & Q & $99 \%$ & $\mathrm{~N}$ & 60.00 & 53.20 \\
\hline Spain & De Paúl et al. (1995) & 403 & S & $\mathrm{L}$ & NP & Q & a & B & 9.70 & 14.8 \\
\hline Sweden & Edgardh and Ormstad (2000) & 2153 & S and $G$ & $\mathrm{~N}$ & $P$ & Q & $92 \%$ students, $44 \%$ general & B & $3.19^{\mathrm{d}}$ & $12.71^{\mathrm{d}}$ \\
\hline \multirow[t]{3}{*}{ Switzerland } & Tschumper et al. (1998) & 3993 & S & $\mathrm{N}$ & $P$ & Q & $>94 \%$ & B & - & 18.60 \\
\hline & Bouvier et al. (1999) & 1116 & S & $\mathrm{L}$ & $P$ & Q & $100 \%$ & B & 10.90 & 33.80 \\
\hline & Niederberger (2002) & 980 & G & $\mathrm{L}$ & $P$ & I & $66 \%$ & B & & 39.80 \\
\hline Turkey & Eskin et al. (2005) & 1256 & S & $\mathrm{L}$ & NP & Q & $100 \%$ & B & 28.10 & \\
\hline \multirow[t]{4}{*}{ United States } & Nelson et al. (1994) & 2332 & S & $\mathrm{L}$ & $\mathrm{P}$ & Q & $82 \%$ & B & 8.10 & 33.10 \\
\hline & Lodico et al. (1996) & 6224 & $\mathrm{~s}$ & $\mathrm{~L}$ & $\mathrm{P}$ & $\mathrm{Q}$ & $>95 \%$ & $\mathrm{~N}$ & 4.10 & 16.5 \\
\hline & Arroyo et al. (1997) & 221 & $\mathrm{~s}$ & $\mathrm{~L}$ & NP & Q & $97 \%$ & a & - & $31.22^{\mathrm{d}}$ \\
\hline & Robin et al. (1997) & 375 & G & $\mathrm{L}$ & NP & $\mathrm{Q}$ & $94 \%$ & $\mathrm{~N}$ & 14 & 49 \\
\hline
\end{tabular}




\begin{tabular}{|c|c|c|c|c|c|c|c|c|c|}
\hline Romero et al. (1999) & 300 & $G$ & $\mathrm{~L}$ & $P$ & 1 & $11 \%$ & $\mathrm{~N}$ & - & 33 \\
\hline Vogeltanz et al. (1999) & 654 & G & $\mathrm{N}$ & $\mathrm{P}$ & I & a & B & - & $20.65^{\mathrm{d}}$ \\
\hline Wyatt et al. (1999) & 586 & G & $\mathrm{L}$ & $\mathrm{P}$ & I & a & $\mathrm{N}$ & - & 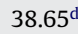 \\
\hline Kenny and McEachern (2000) & 164 & $\mathrm{~s}$ & $\mathrm{~L}$ & NP & I & $96 \%$ & B & - & 18 \\
\hline Back et al. (2003) & 65 & $\mathrm{~s}$ & $\mathrm{~L}$ & NP & $\mathrm{Q}$ & a & $\mathrm{N}$ & - & 50.80 \\
\hline Briere and Elliott (2003) & 935 & G & $\mathrm{N}$ & $P$ & Q & $65 \%$ & $\mathrm{~N}$ & 14.20 & 32.30 \\
\hline Arreola et al. (2005) & 2692 & G & $\mathrm{L}$ & $\mathrm{P}$ & I & $93 \%$ & a & $10.33^{\mathrm{d}}$ & - \\
\hline
\end{tabular}

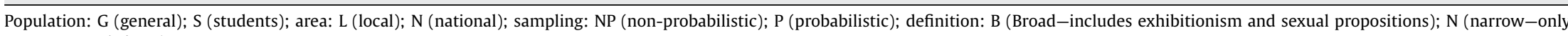
contact sexual abuse).

a (Not reported).

(Not reported).

c Rape-only rape.

d Prevalence per 100: the value is a mean across different subgroups. 
Table 2

Descriptive statistics of the studies reviewed.

\begin{tabular}{lc}
\hline & Percentage \\
\hline Gender $^{\mathrm{a}}$ & \\
Females & 94.87 \\
Males & 58.97 \\
Population & \\
$\quad$ General & \\
Students & 43.59 \\
Parents & 56.41 \\
Area & 2.56 \\
Local & \\
National & 74.36 \\
Sampling & 25.64 \\
$\quad$ Non-probabilistic & \\
Probabilistic & 43.59 \\
Mode of administration & 56.41 \\
Interview & \\
Questionnaire & 25.64 \\
Definition & \\
Broad & 74.36 \\
Narrow & \\
\hline a The sum is not 100 because some studies either include \\
more than one category or have missing values.
\end{tabular}

below $10 \%$, while in the case of females most studies ( 38.10 and $34.29 \%$, in both reviews respectively) locate the prevalence between 10 and $20 \%$. Another $28.57 \%$ of studies, in both Finkelhor's (1994) and the present research, report a prevalence rate of child sexual abuse among women of between 30 and $40 \%$.

As regards the sample of men, Finkelhor (1994) reported prevalence rates below 10\% in a large number of European countries, as well as in Australia and Canada; however, he found higher rates not only in several economically disadvantaged countries (Costa Rica, Dominican Republic, and South Africa) but also in Spain and the USA. In the present review, prevalence rates below $10 \%$ for men were found in many countries in Europe, Asia (China, Malaysia, and New Zealand), and in the USA; prevalence rates above $10 \%$ also corresponded to a wide range of socio-economic situations, with the extremely high rate reported in the South African study being particularly noteworthy.

As regards women, Finkelhor reported prevalence rates of 10-20\% in various European countries and Canada. The present review supports these findings but also found similar rates in the Americas (El Salvador and the USA) and Asia (China, New Zealand, and Singapore). Finkelhor found higher prevalence rates in other European countries, as well as in Australia, Costa Rica, Dominican Republic, New Zealand, South Africa, and the USA, whereas the findings of the present review add Great Britain, Israel, Switzerland, and Turkey to this list.

Given this diversity among both male and female samples, it is difficult to identify patterns across those countries with similar prevalence rates, and therefore child sexual abuse should be regarded as a widespread problem in countries with very different cultural and economic situations.

Comparison of the two reviews reveals what appears to be a general pattern that remains more or less constant over the years, especially in women. However, there are two main differences: in Finkelhor's review there were no studies reporting prevalence rates higher than 50\%, whereas the present review includes two studies, conducted in South Africa and the USA, which do report such rates. Furthermore, the present review includes a higher number of publications that report prevalence rates of $10-20 \%$ for child abuse in men than does Finkelhor's study.

A total of 12 countries provided prevalence data for both Finkelhor's (1994) and the present review. However, as can be seen in Table 3, the rates vary according to the country in question: in some cases the prevalence rates found in the present review were higher than those reported by Finkelhor, while in other cases just the opposite is observed.

Taking together the findings of the two comparative reviews the prevalence of childhood sexual abuse across the 28 countries ranges from 0 to $53 \%$ in women and from 0 to $60 \%$ in men. Fig. 2 shows the distribution of prevalence rates taking both reviews together.

Overall, it can be seen that the most frequent prevalence rate of child sexual abuse for men is below $10 \%$ (in $57.50 \%$ of the studies reviewed), while for females the most frequent rate is between 10 and $20 \%$ (in $35.71 \%$ of the studies). However, almost $30 \%$ of studies report childhood sexual abuse prevalence rates above $30 \%$.

\section{Discussion}

This study examined the prevalence of child sexual abuse since 1994 and compared the findings to those obtained in a comparable review by Finkelhor (1994). The results obtained from a variety of countries suggest that child sexual abuse 
Table 3

Prevalence according to country in the two reviews.

\begin{tabular}{lllll}
\hline Country & \multicolumn{2}{l}{ Men } & & Women \\
\cline { 2 - 4 } & Finkelhor study (1994) & Present study & Finkelhor study (1994) \\
\hline Australia & 9 & 19 & 28 & $39 / 41 / 45$ \\
Canada & 8 & 4 & 18 & 13 \\
Finland & 4 & - & 7 & $1^{\mathrm{a}}$ \\
France & 5 & $1^{\mathrm{b}}$ & 12 & 13 \\
Great Britain & 8 & 11 & 32 & $13 / 21$ \\
New Zealand & - & 3 & 19 & 19 \\
Norway & 9 & 4 & 34 & \\
South Africa & 29 & 60 & 23 & 19 \\
Spain & 15 & 10 & $35 / 53$ \\
Sweden & 3 & 3 & 11 & 13 \\
Switzerland & 3 & 11 & 27 & $19 / 34 / 40$ \\
United States & 16 & $8 / 4 / 14 / 14 / 10$ & $33 / 17 / 31 / 49 / 33 / 21 / 39 / 18 / 51 / 32$ \\
\hline
\end{tabular}

a Incest-only incest.

b Rape-only rape.

remains an international problem. Twelve years ago there was a strong North American and European contribution to the study of child sexual abuse prevalence, this reflecting the level of social science research resources in these countries. Although the present review compared 28 countries from 5 continents, the North American and European contribution is still very important. The prevalence of child sexual abuse remained fairly constant over the 12-year period examined, although differences between studies were common. As stated by Runyan (1998), the ease with which adults in different societies can talk about sexual abuse varies dramatically. The study by Madu and Peltzer (2001) with South African students yielded the highest prevalence rate in the present review. Furthermore, the prevalence rate found among their male subjects (60\%) was higher than that of their female subjects (53.2\%). This is contrary both to popular expectation and to the other studies included in the present review. The authors sought to explain these results through reference to the characteristics of the families in the study area (absence of adult males and frequent single parenthood). It may also be that male participants were more open in reporting their childhood sexual experiences than were females in this study. However, other authors (Finkelhor, 1994; Wynkoop et al., 1995) argue that differences in research methodology account for most of the variance in prevalence rates between studies.

\section{Abuse definition}

Many of the studies reviewed defined child sexual abuse as either contact and non-contact sexual experiences between a person under 18 years of age and an adult or other person at least 5 years older; or sexual experiences resulting from coercion, no matter what the age of the other person. These criteria are based on the classical proposal by Finkelhor and Hotaling (1984), and their use should be encouraged. However, difficulties remain in reaching a consensus on the definition of child maltreatment and sexual abuse (Manly, 2005), in part because it is determined by cultural and community standards (Bradley \& Lindsay, 1987).

In the present review, the study by Choquet et al. (1997) examined the prevalence of rape in France and obtained an extremely low rate. A similarly low result was obtained in the study by Sariola and Uutela (1996). These authors only reported the prevalence of father-daughter and stepfather-daughter incest in Finland, using a very restrictive definition of child sexual abuse. This apparently lower rate of rape among French students may be related to the fact that this type of sexual abuse is not as frequent as other types (such as fondling or kissing) included in the majority of studies reviewed. As

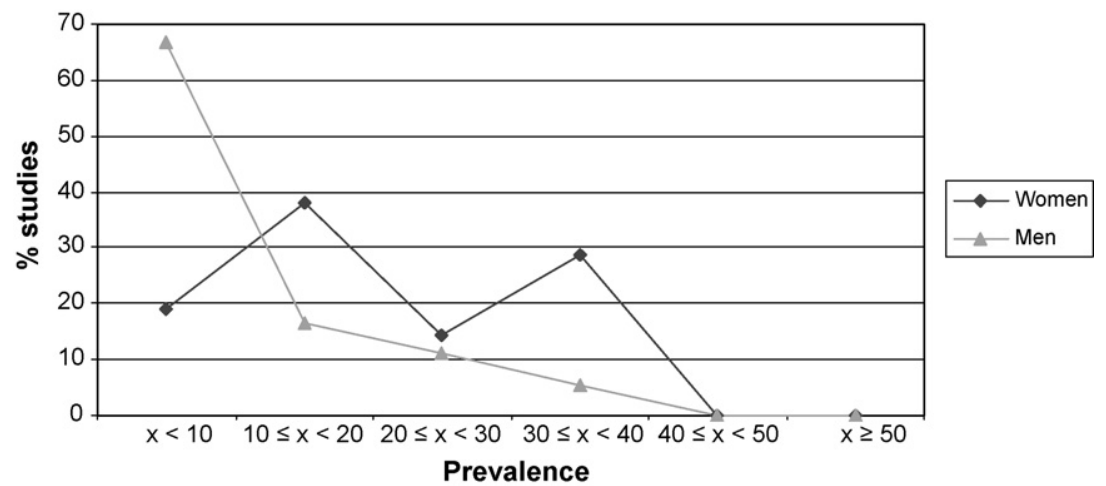

Fig. 2. Percentage of studies according to prevalence rates and gender, taking Finkelhor's and the present review together. 
regards incest, its prevalence cannot be compared with the rates obtained in the other studies reviewed since these studies include the prevalence of child sexual abuse committed by different kinds of aggressors.

\section{Measurement issues}

Most of the studies reviewed used different measures to identify cases of child sexual abuse and their reliability and validity is not always well established. Although some authors have concluded that face-to-face interviews result in higher reporting rates for prevalence (Peters et al., 1986), the present review does not enable us to confirm these results. Although some of the highest prevalence rates were obtained with questionnaires (Back et al., 2003; Madu \& Peltzer, 2001), high rates were also found with interviews (Niederberger, 2002; Wyatt, Loeb, Solis, Carmona, \& Romero, 1999). As stated by other authors, the key requirement is to use instruments (interviews or questionnaires) that have been developed according to accepted psychometric principles, and which are accompanied by data on reliability and validity (Briere, 1992).

Reviews have also found that the use of broad questions is associated with lower prevalence rates of sexual abuse than are more behaviorally specific questions (Fricker et al., 2003). Both the context in which sexual victimization questions are asked (Koss, 1993) and the number of questions asked (Finkelhor, 1979) also affect endorsement rates. In the present review, the highest prevalence rates were observed in studies that used more than one broad question [multiple questions about child maltreatment experiences, as in Madu and Peltzer (2001), and multiple questions about a wide range of traumatic experiences, as in Back et al. (2003)].

The procedure used by studies can also affect the results obtained. For instance, in Figueiredo et al. (2004) the teachers gave their pupils questionnaires on physical and sexual abuse experiences, but these were to be filled in by their parents. The parents had to answer the questionnaire about their own childhood experiences and return them to their children, who then handed back the questionnaires to the teachers. Interestingly, this study yielded the lowest prevalence rates of child sexual abuse found in the present review. In contrast, the study by May-Chahal and Cawson (2005) gathered information about sexual abuse in childhood by using a computer-assisted personal interview. These two procedures are clearly very different, and such differences seem to affect the prevalence rates of child sexual abuse found by each study.

Differences in procedure can also explain the low prevalence rate found in Ross et al. (2005) as compared to the study by Chen et al. (2004). Both studies were conducted in China but their prevalence rates of child sexual abuse were very different. In the study by Ross et al. (2005) the authors interviewed a non-clinical sample of workers at a clothing manufacturing factory and concluded that none of them had suffered child sexual abuse. However, in the study by Chen et al. (2004) $13.5 \%$ of high school students reported unwanted sexually abusive experiences.

\section{Sample characteristics}

The sample surveyed varies among the studies compared (e.g., socio-economic status, age of the respondents, and gender) and this may affect the prevalence rates found. Limited sample size is also a common problem in the child sexual abuse literature, and is present in some of the studies reviewed (Back et al., 2003; Barthauer \& Leventhal, 1999). The study by Back et al. (2003) with North American students reported significantly higher rates of child sexual abuse (50.8\%) as compared to other studies from the USA or other countries. However, the small sample of this study $(n=65)$ makes it difficult to interpret these results. An insufficient number of subjects can result in generalization problems and low external validity, making it hard to draw comparative conclusions.

As stated elsewhere, the gender of participants also affects prevalence rates (Dhaliwal et al., 1996). In the present review, the ratio of female to male victims of sexual abuse in childhood ranges between .89 and 5.50, although most of the studies report ratios above 1, thus illustrating the higher prevalence rates among women (Bouvier et al., 1999; Briere \& Elliott, 2003; Robin et al., 1997). Several factors have been suggested to explain these results. Holmes and Slap (1998) argue that males who have been sexually victimized may be reluctant to divulge their experiences. First, sexually victimized males may consider that it is unmanly to seek help (Dhaliwal et al., 1996; Romano \& De Luca, 2001), since the abuse experience undermines many men's concepts of their masculinity (Holmes et al., 1997). It may also be that men are less likely to label clearly their childhood sexual activity as abusive, since their role in the ideology of sexual abuse has been that of victimizers (Holmes et al., 1997). The traditional social stigma of homosexuality may also contribute to men's reluctance to report sexual victimization (Romano \& De Luca, 2001). Finally, the different nature and characteristics of child sexual abuse experienced by men and women might also affect the lower prevalence rates found in men (Gold, Elhai, Lucenko, Swingle, \& Hughes, 1998). To address these difficulties, clarification and standardization of how investigators ask subjects about and define male sexual abuse is needed (Holmes \& Slap, 1998).

In sum, the strengths of the current review are, firstly, the update it provides of the results obtained by Finkelhor (1994) 12 years ago, his review including information from 21 countries across 5 continents. Secondly, it illustrates that the major methodological problems in child sexual abuse research remain unresolved, this being something which influences the results obtained and makes it impossible to compare data.

However, the fact that the present review is a descriptive study limits the conclusions which can be drawn. In the future, a systematic review will be conducted to extend the present descriptive and comparative study to a meta-analytic approach, the aims being to obtain a worldwide prevalence index of child sexual abuse and to explore the possible influence of different moderator variables (i.e., sample characteristics, mode of administration) on that rate. 


\section{References ( ${ }^{*}$ Published studies included in the present review)}

Aaro, L. E., Wold, B., \& Kannas, L. (1986). Health behavior among school children: A World Health Organization cross-national survey. Health Promotion, 1, $17-33$.

*Alami, M., \& Kadri, N. (2004). Moroccan women with a history of child sexual abuse and its long-term repercussions: A population-based epidemiological study. Archives of Women's Mental Health, 7, 237-242.

*Arreola, S. G., Neilands, T. B., Pollack, L. M., Paul, J. P., \& Catania, J. A. (2005). Higher prevalence of childhood sexual abuse among Latino men who have sex with men than non-Latino men who have sex with men: Data from the Urban Men's Health Study. Child Abuse E Neglect, 29, 285-290.

*Arroyo, J. A., Simpson, T. L., \& Aragon, A. S. (1997). Childhood sexual abuse among Hispanic and Non-Hispanic white college women. Hispanic Journal of Behavioral Sciences, 19(1), 57-68.

*Back, S. E., Jackson, J. L., Fitzgerald, M., Shaffer, A., Salstrom, S., \& Osman, M. M. (2003). Child sexual and physical abuse among college students in Singapore and the United States. Child Abuse \& Neglect, 27, 1259-1275.

*Barthauer, L. M., \& Leventhal, J. M. (1999). Prevalence and effects of child sexual abuse in a poor, rural community in El Salvador: A retrospective study of women after 12 years of civil war. Child Abuse E Neglect, 23(11), 1117-1126.

*Bendixen, M., Muus, K., \& Schei, B. (1994). The impact of child sexual abuse. A study of a random sample of Norwegian students. Child Abuse E Neglect, 18 , 837-847.

Berliner, L., \& Conte, J. R. (1995). The effects of disclosure and intervention on sexually abused children. Child Abuse E Neglect, 19(3), 371-384.

Bernstein, D., Fink, L., Handelsman, L., Foote, J., Lovejoy, M., Wenzel, K., Sapareto, E., \& Ruggiero, J. (1994). Initial reliability and validity of a new retrospective measure of child abuse and neglect. American Journal of Psychiatry, 151, 1132-1136.

Bouvier, P., Halpérin, D., Rey, H., Jaffé, P. D., Laederach, J., Mounoud, R. L., \& Pawlak, C. (1999). Typology and correlates of sexual abuse in children and youth: Multivariate analyses in a prevalence study in Geneva. Child Abuse \& Neglect, 23(8), 779-790.

Bradley, E. J., \& Lindsay, R. C. L. (1987). Methodological and ethical issues in child abuse research. Journal of Family Violence, 2(3), 239-255.

Briere, J. (1992). Methodological issues in the study of sexual abuse effects. Journal of Consulting and Clinical Psychology, 60(2), 196-203.

Briere, J. N. (1993). Child abuse trauma. London: Sage.

Briere, J. (1997). Psychological assessment of adult posttraumatic states. Washington, DC: American Psychological Association.

*Briere, J., \& Elliott, D. M. (2003). Prevalence and psychological sequelae of self-reported childhood physical and sexual abuse in a general population sample of men and women. Child Abuse \& Neglect, 27, 1205-1222.

Brown, T., Frederico, M., Hewitt, L., \& Sheehan, R. (2001). The child abuse and divorce myth. Child Abuse Review, 10, 113-124.

Caritas Family Service. (1996). Study on childhood sexual experiences. Hong Kong: Author.

Chen, J. Q., Dunne, M. P., \& Wang, X. W. (2003). Childhood sexual abuse: An investigation among 239 male high school students. Chinese Mental Health Journal, 17, 345-347.

*Chen, J. Q., Dunne, M. P., \& Han, P. (2004). Child sexual abuse in China: A study of adolescents in four provinces. Child Abuse E Neglect, 28, 1171-1186.

Choquet, M., Ledoux, S., \& Menke, H. (1988). La santé des adolescents. Paris, France: INSERM, Documentation Française.

*Choquet, M., Darves-Bornoz, J.-M., Ledoux, S., Manfredi, R., \& Hassler, C. (1997). Self-reported health and behavioural problems among adolescent victims of rape in France: Results of a cross-sectional survey. Child Abuse E Neglect, 21(9), 823-832.

*Collings, S. J. (1997). Child sexual abuse in a sample of South African women students: Prevalence, characteristics, and long-term effects. South African Journal of Psychology, 27(1), 37-42.

*De Paúl, J., Milner, J. S., \& Múgica, P. (1995). Childhood maltreatment, childhood social support, and child abuse potential in a Basque sample. Child Abuse E Neglect, 19(8), 907-920.

Dhaliwal, G. K., Gauzas, L., Antonowicz, D. H., \& Ross, R. R. (1996). Adult male survivors of childhood sexual abuse, prevalence, sexual abuse characteristics, and long-term effects. Clinical Psychology Review, 16(7), 619-639.

*Edgardh, K., \& Ormstad, K. (2000). Prevalence and characteristics of sexual abuse in a national sample of Swedish seventeen-year-old boys and girls. Acta Paediatrica, 88, 310-319.

*Eskin, M., Kaynak-Demir, H., \& Demir, S. (2005). Same-sex sexual orientation, childhood sexual abuse, and suicidal behavior in university students in Turkey. Archives of Sexual Behavior, 34(2), 185-195.

Falsetti, S. F. (1996). Trauma assessment for adults-self report form. Unpublished instrument. Charleston, SC: Department of Psychiatry and Behavioral Sciences, National Crime Victims Research and Treatment Center, Medical University of South Carolina.

*Fergusson, D. M., Lynskey, M. T., \& Horwood, J. L. (1996). Childhood sexual abuse and psychiatric disorder in young adulthood. I. Prevalence of sexual abuse and factors associated with sexual abuse. Journal of the American Academy of Child and Adolescent Psychiatry, 35(10), 1355-1364.

Fergusson, D. M., Horwood, J. L., \& Woodward, L. J. (2000). The stability of child abuse reports: A longitudinal study of the reporting behavior of young adults. Psychological Medicine, 30, 529-544.

*Figueiredo, B., Bifulco, A., Paiva, C., Maia, A., Fernandes, E., \& Matos, R. (2004). History of childhood abuse in Portuguese parents. Child Abuse E Neglect, 28, 669-682.

Finkelhor, D. (1979). Sexually victimized children. New York: Free Press.

Finkelhor, D. (1986). A source book for child sexual abuse. New York: Sage.

Finkelhor, D. (1994). The international epidemiology of child sexual abuse. Child Abuse E Neglect, 18(5), 409-417.

Finkelhor, D., \& Hotaling, G. T. (1984). Sexual abuse in the National Incidence Study of Child Abuse and Neglect: An appraisal. Child Abuse E Neglect, 8, $23-33$.

Finkelhor, D., Hotaling, G., Lewis, I. A., \& Smith, C. (1990). Sexual abuse in a national survey of adult men and women: Prevalence, characteristics, and risk factors. Child Abuse E Neglect, 14, 19-28.

*Fleming, J. M. (1997). Prevalence of childhood sexual abuse in a community sample of Australian women. Medical Journal of Australia, 166, 65-68.

Fricker, A. E., Smith, D. W., Davis, J. L., \& Hanson, R. F. (2003). Effects of context and question type on endorsement of childhood sexual abuse. Journal of Traumatic Stress, 16(3), 265-268.

Gold, S. N., Elhai, J. D., Lucenko, B. A., Swingle, J. M., \& Hughes, D. M. (1998). Abuse characteristics among childhood sexual abuse survivors in therapy: A gender comparison. Child Abuse \& Neglect, 22(10), 1005-1012.

*Goldman, J. D. G., \& Padayachi, U. K. (1997). The prevalence and nature of child sexual abuse in Queensland, Australia. Child Abuse E Neglect, 21(5), 489-498.

*Halperin, D. S., Bouvier, P., Jaffe, P. D., Mounoud, R. L., Pawlak, C. H., Laederach, J., Wicky, H. R., \& Astie, F. (1996). Prevalence of child sexual abuse among adolescents in Geneva: Results of a cross-sectional survey. British Medical Journal, 312(7042), 1326-1329.

Haskett, M. E., Marziano, B., \& Dover, E. R. (1996). Absence of males in maltreatment research: A survey of recent literature. Child Abuse \& Neglect, 20(12), $1175-1182$

Holmes, W. C., \& Slap, G. B. (1998). Sexual abuse of boys. Definition, prevalence, correlates sequelae, and management. Journal of the American Medical Association, 280(21), 1855-1862.

Holmes, G. R., Offen, L., \& Waller, G. (1997). See no evil, hear no evil, speak no evil: Why do relatively few male victims of childhood sexual abuse receive help for abuse-related issues in adulthood? Clinical Psychology Review, 17(1), 69-88.

*Jumaian, A. (2001). Prevalence and long-term impact of child sexual abuse among a sample of male college students in Jordan. Eastern Mediterranean Health Journal, 7(3), 435-440.

*Kenny, M. C., \& McEachern, A. G. (2000). Prevalence and characteristics of childhood sexual abuse in multiethnic female college students. Journal of Child Sexual Abuse, 9(2), 57-70.

Koss, M. P. (1993). Detecting the scope of rape: A review of prevalence research methods. Journal of Interpersonal Violence, 8, 198-222.

Leventhal, J. M. (1998). Epidemiology of sexual abuse of children: Old problems, new directions. Child Abuse E Neglect, 22(6), 481-491. 
*Lodico, M. A., Gruber, E., \& DiClemente, R. J. (1996). Childhood sexual abuse and coercive sex among school-based adolescents in a Midwestern state. Journal of Adolescent Health, 18, 211-217.

López, F. (1994). Los abusos sexuales de menores. Lo que recuerdan los adultos. Madrid: Ministerio de Asuntos Sociales.

MacMillan, H. L. (1998). Child abuse: A community problem. Canadian Medical Association Journal, 158, 1301-1302.

*MacMillan, H. L., Fleming, J. E., Trocmé, N., Boyle, M. H., Wong, M., Racine, Y. A., Beardslee, W. R., \& Offord, D. R. (1997). Prevalence of child physical and sexual abuse in the community: Results from the Ontario Health Supplement. Journal of the American Medical Association, $278,131-135$.

*Madu, S. N., \& Peltzer, K. (2001). Prevalence and patterns of child sexual abuse and victim-perpetrator relationship among secondary school students in the Northern Province (South Africa). Archives of Sexual Behavior, 30(3), 311-321.

Manly, J. T. (2005). Advances in research definitions of child maltreatment. Child Abuse E Neglect, 29, 425-439.

*May-Chahal, C., \& Cawson, P. (2005). Measuring child maltreatment in the United Kingdom: A study of the prevalence of child abuse and neglect. Child Abuse E' Neglect, 29, 969-984.

*Mazza, D., Dennerstein, L., \& Ryan, V. (1996). Physical, sexual and emotional violence against women: A general practice-based prevalence study. Medical Journal of Australia, 164, 14-17.

Milner, J. S., Robertson, K. R., \& Rogers, D. L. (1990). Childhood history of abuse and adult child abuse potential. Journal of Family Violence, 5, 15-34.

*Nelson, D. E., Higginson, G. K., \& Grant-Worley, J. A. (1994). Using the Youth Risk Behavior Survey to estimate prevalence of sexual abuse among Oregon high school students. The Journal of School Health, 64(10), 413-416.

*Niederberger, J. M. (2002). The perpetrator's strategy as a crucial variable: A representative study of sexual abuse of girls and its sequelae in Switzerland. Child Abuse \& Neglect, 26, 55-71.

*Oaksford, K. L., \& Frude, N. (2001). The prevalence and nature of child sexual abuse: Evidence from a female university sample in the UK. Child Abuse Review, $10,49-59$.

Oates, R. K., Jones, D. P. H., Denson, D., Sirotnak, A., Gary, N., \& Krugman, R. D. (2000). Erroneous concerns about child sexual abuse. Child Abuse E Neglect, 24(1), 149-157.

Peters, S. D., Wyatt, G. E., \& Finkelhor, D. (1986). Prevalence. In D. Finkelhor (Ed.), A source book on child sexual abuse (pp. 15-59). Newbury Park, CA: Sage.

Pincus, H. A., Rush, J. A., First, M. B., \& McQueen, L. E. (2000). Handbook of psychiatric measures. Washington, DC: American Psychiatric Association.

*Robin, R. W., Chester, B., Rasmussen, J. K., Jaranson, J. M., \& Goldman, D. (1997). Prevalence, characteristics, and impact of childhood sexual abuse in a southwestern American Indian tribe. Child Abuse E' Neglect, 21(8), 769-787.

Romano, E., \& De Luca, R. V. (2001). Male sexual abuse: A review of effects, abuse characteristics, and links with later psychological functioning. Aggression and Violent Behavior, 6, 55-78.

*Romero, G. J., Wyatt, G. E., Loeb, T. B., Carmona, J. V., \& Solis, B. M. (1999). The prevalence and circumstances of child sexual abuse among Latina women. Hispanic Journal of Behavioral Sciences, 21(3), 351-365.

*Ross, C. A., Keyes, B. B., Xiao, Z., Yan, H., Wang, Z., Zou, Z., Xu, Y., Chen, J., \& Zhang, H. (2005). Childhood physical and sexual abuse in China. Journal of Child Sexual Abuse, 14(4), 115-126.

Runyan, D. K. (1998). Prevalence, risk, sensitivity and specificity: A commentary on the epidemiology of child sexual abuse and the development of a research agenda. Child Abuse E' Neglect, 22(6), 493-498.

Russell, D. E. H. (1983). The incidence and prevalence of intrafamilial and extrafamilial sexual abuse of female children. Child Abuse E Neglect, 7, 133-146.

*Sariola, H., \& Uutela, A. (1996). The prevalence and context of incest abuse in Finland. Child Abuse E' Neglect, 20(9), 843-850.

*Schein, M., Biderman, A., Baras, M., Bennett, L., Bisharat, B., Borkan, J., Fogelman, Y., Gordon, L., Steinmetz, D., \& Kitai, E. (2000). The prevalence of a history of child sexual abuse among adults visiting family practitioners in Israel. Child Abuse E Neglect, 24(5), 667-675.

*Singh, A., Yiing, W. W., \& Nurani, N. K. (1996). Prevalence of childhood sexual abuse among Malaysian paramedical students. Child Abuse E Neglect, 20(6), 487-492.

*Tang, C. S. (2002). Childhood experiences of sexual abuse among Hong Kong Chinese college students. Child Abuse E Neglect, $26,23-37$.

*Tschumper, A., Narring, F., Meier, C., \& Michaud, P. A. (1998). Sexual victimization in adolescent girls (age 15-20 years) enrolled in post-mandatory schools of professional training programmes in Switzerland. Acta Paediatrica, 87, 212-217.

Violato, C., \& Genuis, M. (1993). Problems of research in male child sexual abuse: A review. Journal of Child Sexual Abuse, 2 (3), 33-54.

*Vogeltanz, N. D., Wilsnack, S. C., Harris, T. R., Wilsnack, R. W., Wonderlich, S. A., \& Kristjanson, A. F. (1999). Prevalence and risk factors for childhood sexual abuse in women: National survey findings. Child Abuse E Neglect, 23(6), 579-592.

Wolfe, V. V., \& Birt, J. (1997). Child sexual abuse. In E. J. Mash, \& L. G. Terdal (Eds.), Assessment of childhood disorders (pp. 569-623). New York: The Guilford Press.

Wyatt, G. E. (1985). The sexual abuse of Afro-American and White-American women in childhood. Child Abuse E' Neglect, 9, $507-519$.

Wyatt, G. E., \& Peters, S. D. (1986). Issues in the definition of child sexual abuse in prevalence research. Child Abuse E' Neglect, 10, 231-240.

*Wyatt, G. E., Loeb, T. B., Solis, B., Carmona, J. V., \& Romero, G. (1999). The prevalence and circumstances of child sexual abuse: Changes across a decade. Child Abuse \& Neglect, 23(1), 45-60.

Wynkoop, T. F., Capps, S. C., \& Priest, B. J. (1995). Incidence and prevalence of child sexual abuse: A critical review of data collection procedures. Journal of Child Sexual Abuse, 4(2), 49-67.

\section{Appendix A. Annotations to Table 1}

Australia. A national study of the prevalence of child sexual abuse was conducted in Australia in 1994 (Fleming, 1997). This work was part of a two-stage, case-control investigation into the relationship between sexual abuse in childhood and alcohol abuse. Only women were selected. The definition of sexual abuse included two narrow criteria: experiences of sexual contact before the age of 12 with someone at least 5 years older, and all experiences of sexual contact occurring between the ages of 12 and 16 with someone 5 or more years older and which were unwanted or distressing. The other two published studies examined the prevalence of childhood sexual abuse in women attending general practitioners (Mazza, Dennerstein, \& Ryan, 1996), and male and female undergraduate students (Goldman \& Padayachi, 1997). The questions used by Mazza et al. (1996) to assess childhood sexual abuse were derived from the previous studies of Wyatt (1985) and Russell (1983), and included contact and non-contact sexual experiences. For their part, Goldman and Padayachi (1997) applied a modified version of Finkelhor's (1979) questionnaire. The three studies obtained similar rates of sexual abuse experiences in childhood.

Canada. This article from MacMillan et al. (1997) presents findings from the Ontario Health Supplement (OHS) on the prevalence of physical and sexual abuse in a large population sample. Considering child maltreatment to be a major public health problem, the Ontario Health Survey (OHS) was sponsored by the Ontario Ministry of Health to collect information about the physical health of Ontario residents. An unpublished self-administered questionnaire was used to assess physical and sexual abuse histories. 
China. Much of the research conducted in Asia has examined the prevalence of sexual abuse in Chinese populations. Two studies obtained information about the childhood sexual experiences of student samples in Hong Kong (Tang, 2002) and in Hubei, Henan, Hebei, and Beijing provinces (Chen et al., 2004). Both used questionnaires adapted from previous Western (e.g., Finkelhor, 1986; Fleming, 1997) and local studies (e.g., Caritas Family Service, 1996; Chen, Dunne, \& Wang, 2003). In the same context, the study of Ross et al. (2005) determined low rates of reported childhood sexual abuse among inpatients (2.8\%) and outpatients (3.0\%) at a mental health centre in Shanghai. They also examined a non-clinical sample of workers, who reported no childhood sexual abuse. The authors obtained these results with the Dissociative Disorders Interview Schedule, which also inquires about childhood sexual experiences (Pincus, Rush, First, \& McQueen, 2000).

El Salvador. This study was conducted in a rural community in the developing nation of El Salvador. A small group of Salvadorian women responded to an interview based on the Spanish translation of the "History of child sexual abuse questionnaire" (Finkelhor et al., 1990).

Finland. This is part of a large study included in Finkelhor's (1994) review, in which the authors assessed the prevalence of sexual abuse among Finnish male and female secondary students. In the study reviewed here, Sariola and Uutela (1996) only included those cases of females reporting incest by their father or stepfather.

France. A national representative sample of adolescent students filled out a questionnaire derived from the Choquet, Ledoux, and Menke (1988) and the WHO HBSC study (World Health Organization, Health Behavior among School Children; Aaro, Wold, \& Kannas, 1986). Only one dichotomous yes-no question concerned rape (attempted rape, rape, or another sexual assault).

Great Britain. One study measured both intra- and extra-familial child maltreatment in a national sample of young adults obtained by random probability sampling (May-Chahal \& Cawson, 2005). Respondents were asked, among other questions, whether they had experienced specific forms of sexual behavior (from being shown pornography to sexual intercourse). Abuse was defined by three criteria: the relationship between the respondent and the aggressor, the fact that the behavior occurred against the respondent's will, and a difference of 5 years or more between the aggressor and the respondent when the latter was aged 12 years or under. The other study established the prevalence of sexual abuse in a female university sample in Wales (Oaksford \& Frude, 2001). The only question used to examine the prevalence of sexual abuse defined it as any sexual experiences before the age of 16 that the respondent consider abusive.

Israel. There is just one published study about the prevalence of child sexual abuse in Israeli adults visiting family practitioners. No studies from this country were included in the review of Finkelhor (1994). The authors (Schein et al., 2000) defined sexual abuse by using five specific questions identified in the literature as childhood sexual experiences, including contact (fondling, oral-genital contact, attempted and completed sexual intercourse) and non-contact sexual forms (exhibitionism). The prevalence of sexual abuse found was similar to that reported by other studies carried out in Western countries (Finkelhor, 1994).

Jordan. One study with a male sample of Jordan college students was published after Finkelhor's (1994) review. A narrow definition of sexual abuse was used, including all contact sexual experiences before the age of 14 years with a person at least 5 years older. The prevalence of child sexual abuse obtained is the highest reported in Eastern countries.

Malaysia. This is one of the few studies of child sexual abuse conducted in Asia since 1994. A self-administered questionnaire was used with a group of paramedical students (nurses and medical assistants). The survey included a broad definition of sexual abuse: contact and non-contact sexual experiences in an intra- or extra-familial setting when the respondent was younger than 18 years of age. The prevalence of sexual abuse was lower than rates obtained in industrialized countries. The authors considered that this may reflect particular limitations in this country as regards the reporting of sexual abuse.

Morocco. No study with a Moroccan population was included in Finkelhor's review (1994). However, Alami and Kadri (2004) have recently reported the prevalence of sexual abuse in women from Casablanca. A broad definition of childhood sexual experiences was used, including conversations of a pornographic nature, as well as penetration or attempted penetration. The prevalence of sexual abuse was in line with that obtained in other countries.

New Zealand. This study is part of the Christchurch Health and Development Study conducted in the urban region of Christchurch during mid-1977. Children were studied at different points of their life, concluding with a final interview at age 18 that included questions of sexual abuse experiences. The definition of sexual abuse included contact and non-contact activities before the age of 16 against the will of the respondent.

Norway. Only one local study has been published on the prevalence of child sexual abuse in Norway since 1994. College and university students from the city of Trondheim were questioned about the experience of sexual acts in which the respondent was forced, coerced or tricked, or involved as a child in acts which adults ought not to do with children.

Portugal. This is the first retrospective study of childhood abuse in a large sample of parents randomly selected from five public elementary schools in the north of Portugal. The Childhood History Questionnaire (Milner, Robertson, \& Rogers, 1990) was used to examine the prevalence of physical and sexual abuse and care during childhood (before age 13) and adolescence (after age 13). The results showed a prevalence rate of sexual abuse of $1.3 \%$ before age 13 only, . $7 \%$ after age 13 only, and .6 before and after age 13. This study reports lower rates than those obtained in other studies using the same measure (De Paúl et al., 1995; Milner et al., 1990).

Singapore. One study examined the prevalence of sexual abuse in two small groups of undergraduate students from two different countries, the Asian nation of Singapore and the USA. To assess child sexual abuse and other traumatic experiences, a modified version of the Trauma Assessment for Adults-Self Report Form (Falsetti, 1996) was used. This included three items with a narrow definition of sexually abusive experiences: sexual contact before the age of 13 with someone at least 
5 years older, verbally coerced sexual contact before age 18 , and physically coerced sexual contact before the age of 18 . A significantly lower rate of sexual abuse was reported by Singaporean students when compared to their North American counterparts (more than three times higher).

South Africa. Two studies with sexual abuse victims have been published in South Africa during the last decade. Both reported high prevalence rates in students (university and secondary), using a narrow definition of sexual abuse. Collings (1997) included all unwanted sexual experiences involving physical contact experienced by a child of 17 years or younger. Madu and Peltzer (2001) used an abbreviated and modified form of the Child Maltreatment Interview Schedule (Briere, 1993), which also included contact sexual experiences before the age of 17 with an adult or person at least 5 years older or a person in a position of power.

Spain. No national study of child sexual abuse has been conducted in Spain since López (1994). The study of De Paúl et al. (1995) examined childhood experiences of physical and sexual abuse in a Basque undergraduate sample. The authors gathered information about childhood experiences using the Spanish version of the Childhood History Questionnaire (Milner et al., 1990). They found that 3.9\% of male students and $6.4 \%$ of female students reported sexual abuse before age 13 only, while $2.9 \%$ of male students and $3.7 \%$ of female students reported sexual abuse after age 13 only; related figures were that $2.9 \%$ of male students and $4.7 \%$ of female students reported sexual abuse before and after age 13 . Similar rates of child sexual abuse were obtained for the Basque and North American female samples (Milner et al., 1990), although the reported sexual abuse rate for Basque males was more than double that found for their North American counterparts.

Sweden. This study was part of an investigation into adolescent health and consensual sexual behaviors undertaken by the Swedish National Board of Education in 1990. The study included one question defining sexual abuse as a sexual experience against the will of the respondent, with someone at least 5 years older; this question had 10 alternative answers.

Switzerland. The three studies from Switzerland have all focused on young students. The Swiss Multicentre Adolescent Survey on Health (SMASH) is the first national survey in this country to have estimated the prevalence of a history of sexual victimization among adolescents (Tschumper, Narring, Meier, \& Michaud, 1998). The study focuses only on girls and describes sexual victimization as any sexual act that the other person should not have performed. Another study has analyzed the prevalence of sexual abuse in young women from a representative sample of communities from the German-speaking part of Switzerland (Niederberger, 2002). Abuse was defined similarly, as any sexual interaction involving the child before the age of 16 . Acts were not categorized as abuse if it occurred between children and the respondent considered them to be a game or when she felt free to participate. Furthermore, for the episode to qualify as abuse, non-consent was required when the girl was older than 12 . Only one study has examined the prevalence of child sexual abuse in both sexes (Halperin et al., 1996). The authors assessed the experiences of sexual abuse with a list of common forms (from exposure of genitalia to full sexual intercourse).

Turkey. One study related the prevalence of sexual abuse with self-reported same-sex sexual orientation in university students in Turkey. The authors translated and adapted five items from the Childhood Trauma Questionnaire (Bernstein et al., 1994) to assess child sexual abuse, using a broad definition of these experiences. Eskin, Kaynak-Demir, and Demir (2005) concluded that the prevalence of both same-sex sexual behavior and childhood sexual abuse was consistent with results from other studies.

United States. Several studies have been published since 1994 on the prevalence and characteristics of child sexual abuse in the USA. Two of these report recent national surveys of the general population (Briere \& Elliott, 2003; Vogeltanz et al., 1999). Vogeltanz et al. (1999) used the criteria of Wyatt (1985) and Russell (1983) to identify child sexual experiences, while Briere and Elliott (2003) applied the Traumatic Events Survey (Briere, 1997). Many studies have examined the prevalence of child sexual abuse among community samples of Hispanics and Latinos (Arreola et al., 2005; Arroyo, Simpson, \& Aragon, 1997; Romero, Wyatt, Loeb, Carmona, \& Solis, 1999), American Indians (Robin et al., 1997), and African Americans (Wyatt et al., 1999). Arreola et al. (2005) used a telephone interview to enquire about any unwanted sexual experiences among adults from four cities (San Francisco, New York, Los Angeles, and Chicago). Romero et al. (1999) used Wyatt's (1985) definition of child sexual abuse. Robin et al. (1997) used a narrow definition including direct physical sexual contact with a victim prior to the age of 16 by a perpetrator at least 5 years older than the victim. Other studies were based on school samples from different states (Lodico, Gruber, \& DiClemente, 1996; Nelson, Higginson, \& Grant-Worley, 1994) and ethnic groups (Kenny \& McEachern, 2000). Lodico et al. (1996) assessed childhood sexual abuse and coercive sex as those unwanted sexual contacts committed in an intra- or extra-familial setting by an adult, an older person or a friend. Nelson et al. (1994) used one question to determine whether the respondent was a victim of sexual abuse, including contact and non-contact forms. Kenny and McEachern (2000) defined childhood sexual abuse as any wanted or unwanted sexual experience with a significantly older individual while the respondent was under the age of 18. Other studies have compared the prevalence of sexual abuse in students from different countries, such as the USA and Singapore (Back et al., 2003), using a modified version of the Trauma Assessment for Adults-Self Report Form (Falsetti, 1996). 